\title{
Intra-patient potassium variability after hypothermic cardiac arrest: a multicentre, prospective study
}

\author{
M. Pasquier ${ }^{1 *}$ (D, M. Blancher², S. Buse ${ }^{2}$, B. Boussat ${ }^{2}$, G. Debaty ${ }^{2}$, M. Kirsch ${ }^{3}$, M. de Riedmatten ${ }^{4}$, P. Schoettker ${ }^{5}$, \\ T. Annecke ${ }^{6}$ and P. Bouzat ${ }^{7}$
}

\begin{abstract}
Background: To date, the decision to set up therapeutic extra-corporeal life support (ECLS) in hypothermia-related cardiac arrest is based on the potassium value only. However, no information is available about how the analysis should be performed. Our goal was to compare intra-individual variation in serum potassium values depending on the sampling site and analytical technique in hypothermia-related cardiac arrests.

Methods: Adult patients with suspected hypothermia-related refractory cardiac arrest, admitted to three hospitals with ECLS facilities were included. Blood samples were obtained from the femoral vein, a peripheral vein and the femoral artery. Serum potassium was analysed using blood gas (BGA) and clinical laboratory analysis (CL).

Results: Of the 15 consecutive patients included, 12 met the principal criteria, and 5 (33\%) survived. The difference in average potassium values between sites or analytical method used was $\leq 1 \mathrm{mmol} / \mathrm{L}$. The agreement between potassium values according to the three different sampling sites was poor. The ranges of the differences in potassium using BGA measurement were -1.6 to $+1.7 \mathrm{mmol} / \mathrm{L} ;-1.18$ to $+2.7 \mathrm{mmol} / \mathrm{L}$ and -0.87 to $+2 \mathrm{mmol} / \mathrm{L}$ when comparing respectively central venous and peripheral venous, central venous and arterial, and peripheral venous and arterial potassium.

Conclusions: We found important and clinically relevant variability in potassium values between sampling sites. Clinical decisions should not rely on one biological indicator. However, according to our results, the site of lowest potassium, and therefore the preferred site for a single potassium sampling is central venous blood. The use of multivariable prediction tools may help to mitigate the risks inherent in the limits of potassium measurement.
\end{abstract}

Trial registration: ClinicalTrials.gov Identifier: NCT03096561.

Keywords: Cardiac arrest, ECMO, ECPR, Gasometer analyser, hypothermia, accidental, Potassium, Resuscitation, Triage

\section{Background}

Accidental hypothermia, which is often caused by homelessness or substance abuse, mountaineering accidents or suicide attempts, is a condition associated with significant mortality $[1,2]$. However, patients with accidental hypothermic cardiac arrest (CA) may have an excellent neurological outcome after extracorporeal life support (ECLS) rewarming [3, 4]. The critical decision

\footnotetext{
* Correspondence: Mathieu.Pasquier@chuv.ch

${ }^{1}$ Emergency Department, Lausanne University Hospital, Lausanne, Switzerland

Full list of author information is available at the end of the article
}

to initiate rewarming of a CA patient must be made rapidly, based on a very limited amount of information and ancillary examination, while the patient is undergoing cardiopulmonary resuscitation (CPR). For clinicians, it is challenging to distinguish between hypothermic cardiac arrest that would benefit from ECLS and a cold, dead person for whom resuscitation would be futile. According to international recommendations, the decision to initiate ECLS for hypothermic CA patients is essentially based on the serum potassium level, since a high serum potassium value is associated with a poor outcome in these patients $[1,2,5-10]$. 
Despite the well-established role of serum potassium in the triage of hypothermic CA victims [1, 8-10], no recommendation exists regarding the site (arterial, venous, central or peripheral) of blood sampling for potassium measurement. Similarly, the type of analytical technique (e.g. by blood gas analysis [BGA] or by the hospital central laboratory) is also not specified. Variation in potassium concentration may, however, occur depending on the site of sampling due to local factors [11-14], or measurement technique [15-18]. Improving our knowledge on this topic is of the utmost importance. Indeed, if a life-or-death decision has to be made based on a single biological indicator, this measurement should be perfectly reliable. Our goal was to study the potassium concentration at different sampling sites (central venous, peripheral venous and arterial) and by different analytical methods (gasometry and laboratory) among hypothermic CA patients. Our hypothesis was that potassium concentrations will vary depending on the sampling site but also on the analytical method used.

\section{Methods}

\section{Patients}

We included consecutive adult patients with refractory CA related to a suspicion of deep hypothermia (core temperature $<30^{\circ} \mathrm{C}$ at hospital admission) from November 2016 to February 2019. We excluded pregnant women and patients with traumatic cardiac arrest. The participating centres were two tertiary care university hospitals (Grenoble, France and Lausanne, Switzerland) and one non-university trauma centre (Sion, Switzerland). The three hospitals have ECLS rewarming capacities. The study was approved by the institutional review board of the participating centres (CER-VD $\mathrm{N}^{\circ}$ 201601760 and ID-RCB: 2016-A01762-49). This study was registered in the ClinicalTrials.gov registry (Identifier: NCT03096561).

\section{Hospital management of patients}

Patients were included at hospital admission. Core temperature was measured in the lower third of the oesophageus $[1,8]$ to confirm hypothermia $<30{ }^{\circ} \mathrm{C}$. Blood samples were obtained at hospital admission from the following three sites: the femoral vein, the femoral artery and a peripheral vein. Central (femoral) samples were obtained either under ultrasound guidance while interrupting CPR or through intravascular catheters. Blood samples were analysed by the following two different analytic methods: BGA and by the hospital central laboratory (CL). The lowest value of the three potassium samples analysed by BGA was used in the decision process to qualify or disqualify patients for ECLS rewarming.

\section{Biological sampling and analysis}

We used heparinized syringes (BD A-line ${ }^{\mathrm{Tm}}$ ) to collect whole blood from each of the three sampling sites for BGA (ABL-800, Radiometer). Potassium was measured using a selective-ion electrode (potentiometry). We also collected the following results: lactate, $\mathrm{pH}, \mathrm{PaCO}_{2}$ and $\mathrm{PaO}_{2}$. BGA is available in the emergency department and allows immediate determination of potassium concentration at the bedside. For CL analysis, blood samples were collected in 2 different sample tubes (BD Vacuitainer $^{\oplus}$ - SST ${ }^{\mathrm{TM}}$ II and BD - LH PST II). Potassium was measured using indirect potentiometry (VISTA ${ }^{\circ}$ SIEMENS V-LYTE ${ }^{\bullet}$ integrated multisensor technology PN797800.002 Rev. D - Siemes healthcare diagnostic 2013). We also measured $\mathrm{pH}$ and lactate. During the study period, the BGA and CL analysers were checked and calibrated regularly according to the manufacturer's recommendations. The time of each of the biological samplings was recorded.

\section{Data collection}

The following prehospital variables of interest were collected for each patient when available: age, gender, prehospital core temperature, whether or not CA was witnessed, time of $\mathrm{CA}$, if asphyxia was associated, first documented cardiac rhythm after CA (e.g. asystole, ventricular fibrillation, pulseless ventricular tachycardia and pulseless electrical activity (PEA)) and prehospital treatments administered (e.g. defibrillation, reanimation drugs). The time of hospital admission and first oesophageal temperature $\left({ }^{\circ} \mathrm{C}\right)$ were collected. When relevant, the modality of hospital rewarming, the no-flow and low-flow duration, as well as the time of ICU and hospital discharge were collected. Patient outcomes were assessed by survival and neurological status at hospital discharge and at 3 months. The neurological outcome was assessed by the Cerebral Performance Category (CPC) [19]. A CPC of 1 or 2 was considered as a "favorable neurological outcome" [4, 20, 21].

\section{Outcomes}

Our primary outcome was the comparison between central venous and peripheral venous potassium by BGA. Secondary outcomes were the comparison between venous and arterial potassium and the comparison between BGA and CL analysis.

\section{Statistical analysis}

The sample size was calculated to detect a difference of at least $1 \mathrm{mmol} / \mathrm{L}$ in the average potassium concentration between central and peripheral venous samples. Using an estimated standard deviation of 3.5, a correlation rate of $95 \%$, an alpha risk level of 0.05 and a power of $80 \%$, the total number of patients was estimated at 12 . 
Cases with missing data regarding the primary outcome (central and/or peripheral venous potassium) in both laboratory and gasometry samples were excluded from the comparative analysis. When BGA data were missing (peripheral or central venous potassium rate), they were replaced by CL data. Descriptive statistics were determined for variables of interest collected from all included patients and expressed as frequencies, means and standard deviations, or medians and interquartile ranges (IQR). Comparisons were conducted by using the Student's $t$-test or the Wilcoxon rank-sum test for appariated data as appropriate, to compare potassium levels between 1) central and peripheral venous sites, 2) venous and arterial sampling and 3) laboratory and gasometry analysis. The concordance between the groups including these individual data was evaluated graphically using Bland and Altmann graphs [22]. A bilateral $P$ value of $<0.05$ was considered to indicate a significant difference between patient groups. Data were retrieved from the patient information database that was established for this study and exported into Stata Special Edition version 14.0 (Stata Corporation, College Station, TX, USA) for analysis.

\section{Results}

Within the study period, we enrolled 15 consecutive patients. Two cases were exluded from the analysis because of missing data regarding the primary outcome (Flow chart in Fig. 1). Overall characteristics of the included patients are presented in Table 1. The mean age was $53 \pm 17$ years (range 25-87), and $60 \%$ of the patients were male $(n=9)$. CA was witnessed in $33 \%(n=5)$. The mean prehospital oesophageal temperature was $22.1 \pm$ $5.8^{\circ} \mathrm{C}$ (range $8-28.3$ ), and the mean hospital oesophageal temperature was $22.0 \pm 5.1{ }^{\circ} \mathrm{C}$ (range 10.7-28.3). Median arterial lactate was $8.60 \mathrm{mmol} / \mathrm{L}$ (IQR 4.9-12.92, range 2.2-22.5). Eleven of the 15 patients (73\%) underwent ECLS: 8 patients had hospital return of a spontaneous circulation (ROSC), and 5 patients survived to hospital discharge (33\%) with a good neurological outcome (3month CPC of 1) for all 5 survivors.

A summary of the potassium values by sampling site and analytic method used is provided in Table 2 . The ranges of the differences in potassium for the 3 different sites using BGA measurement were -1.6 to $+1.7 \mathrm{mmol} /$ $\mathrm{L} ;-1.18$ to $+2.7 \mathrm{mmol} / \mathrm{L}$ and -0.87 to $+2 \mathrm{mmol} / \mathrm{L}$ when comparing, respectively, central venous and

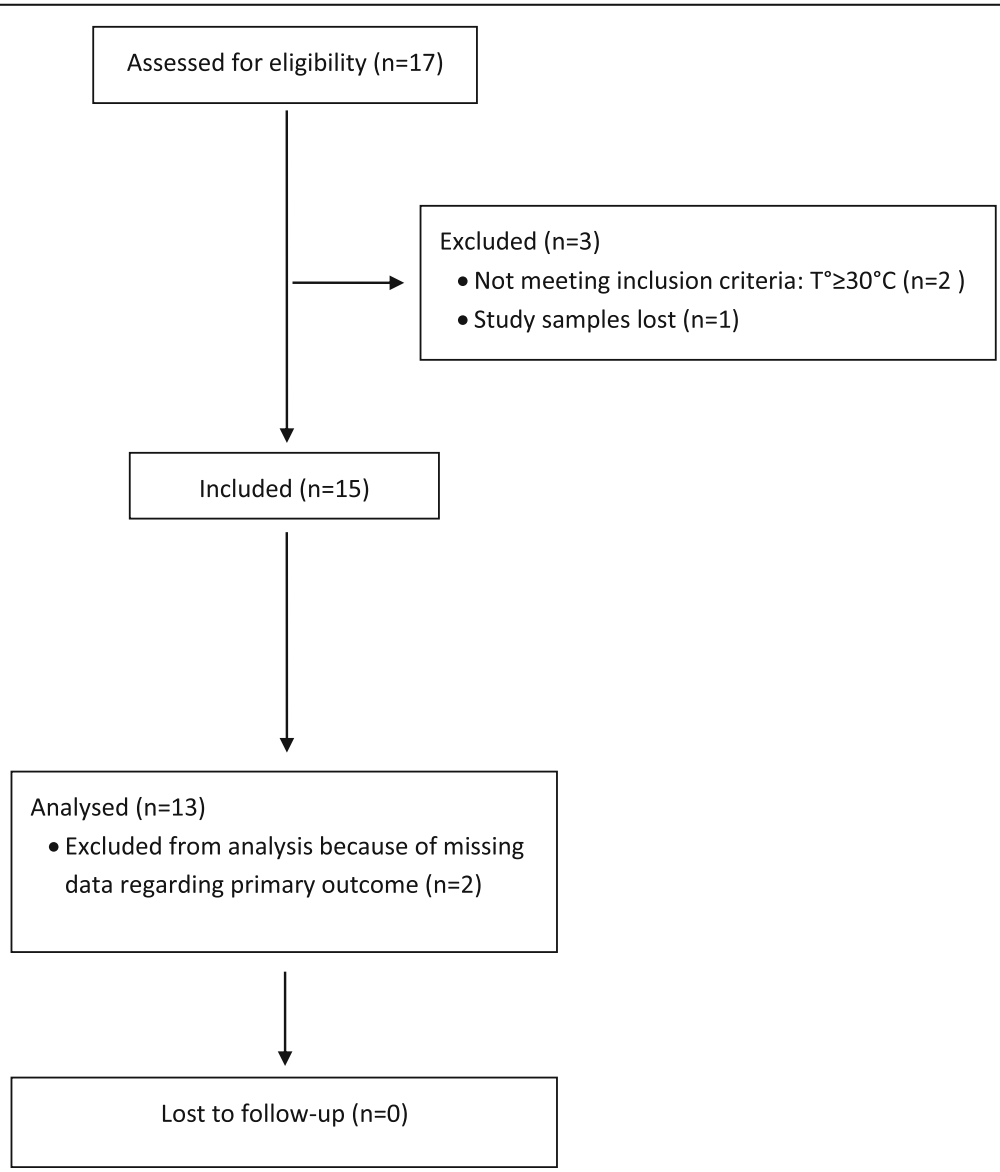

Fig. 1 Flow chart of study patients 
Table 1 Overall characteristics of the included patients $(n=15)$. A asystole, CA cardiac arrest, CPC Cerebral Performance Category, $C P R$ cardiopulmonary resuscitation, ECLS extracorporeal life support, $F$ female, $M$ male, NA not available (including haemolysis), $P E A$ pulseless electrical activity, ROSC return of spontaneous cardiac circulation, VF ventricular fibrillation

\begin{tabular}{|c|c|c|c|c|c|c|c|c|c|c|c|c|c|c|c|}
\hline Patient & $\# 1$ & $\# 2 a$ & \#3 & $\# 4 a$ & $\# 5 b$ & $\# 6$ & \#7 & \#8 & $\# 9$ & $\# 10$ & $\# 11 b$ & $\# 12$ & $\# 13$ & $\# 14$ & $\# 15$ \\
\hline Age & 87 & 32 & 44 & 52 & 57 & 45 & 53 & 41 & 76 & 74 & 49 & 64 & 25 & 35 & 61 \\
\hline Gender & $\mathrm{F}$ & $\mathrm{F}$ & M & M & $\mathrm{F}$ & M & M & $\mathrm{F}$ & M & M & M & M & M & $\mathrm{F}$ & $\mathrm{F}$ \\
\hline Asphyxia $C A^{a}$ & No & No & No & Yes & No & No & No & NA & No & No & No & No & Yes & No & No \\
\hline No-flow duration (min) & 0 & 10 & 0 & 180 & 0 & NA & NA & NA & NA & 1 & 5 & 0 & 18 & 0 & 0 \\
\hline Initial core temperature $\left({ }^{\circ} \mathrm{C}\right)$ & 25.0 & 24.0 & 25.0 & 24.7 & 24.1 & 11.0 & 8.0 & 25.6 & 17.0 & 26.0 & 25.0 & 19.9 & 24.0 & 24.3 & 28.3 \\
\hline First recorded rhythm & VF & A & VF & NA & VF & A & A & NA & A & A & VF & A & A & PEA & VF \\
\hline CPR duration (low flow min) & 10 & 78 & 215 & 38 & 43 & NA & NA & 165 & 99 & 54 & 145 & 117 & 87 & 45 & 55 \\
\hline \multicolumn{16}{|l|}{ Blood gas analyser } \\
\hline Central venous potassium & 3.5 & NA & 4.5 & NA & NA & 10.0 & 14.6 & 5.9 & 9.2 & 2.2 & 4.9 & 3.5 & 4.2 & 2.6 & 2.7 \\
\hline Peripheral venous potassium & 4.25 & NA & 4.9 & NA & 3.0 & 10.4 & 13.0 & 6.4 & 8.4 & 3.9 & NA & 3.6 & 5.1 & 2.6 & 3.7 \\
\hline Arterial potassium & 3.70 & 14.80 & 4.5 & 11.2 & 4.6 & 11.8 & 15.0 & 5.5 & 9.8 & 4.9 & 3.7 & 4.2 & NA & 2.5 & 2.9 \\
\hline $\mathrm{pH}$ & 7.3 & 6.4 & 6.9 & NA & 7.1 & 7.0 & 6.9 & NA & 6.9 & 7.0 & 7.1 & 7.2 & NA & 7.2 & 7.3 \\
\hline Arterial lactates & 11.2 & 22.5 & 3.5 & 16.1 & 4.9 & 12.9 & 8.6 & 18.2 & 9.6 & 5.0 & 8.6 & 6.9 & NA & 3.7 & 2.2 \\
\hline \multicolumn{16}{|l|}{ Central laboratory } \\
\hline Central venous potassium & 3.4 & NA & NA & NA & 3.8 & 11.3 & NA & 6.4 & 9.0 & 2.1 & 4.7 & 3.3 & 4.2 & 3.1 & 3.1 \\
\hline Peripheral venous potassium & 4.6 & NA & NA & NA & 4.2 & NA & 17.2 & 6.4 & 9.1 & 2.3 & 3.4 & 3.5 & 5.5 & 3.0 & 3.7 \\
\hline Arterial potassium & 4.0 & NA & NA & NA & 4.9 & 13.3 & 19.0 & 6.4 & 10.3 & 4.3 & 4.8 & 4.2 & NA & 3.0 & 3.3 \\
\hline \multicolumn{16}{|l|}{ Outcome } \\
\hline ECLS & No & No & Yes & No & Yes & Yes & No & Yes & Yes & Yes & Yes & Yes & Yes & Yes & Yes \\
\hline ROSC & Yes & No & Yes & Yes & No & Yes & No & No & Yes & Yes & No & Yes & Yes & Yes & No \\
\hline Survival at hospital discharge & No & No & No & No & No & No & No & No & No & No & Yes & Yes & Yes & Yes & Yes \\
\hline CPC at 3 months for survivors & NA & NA & NA & NA & NA & NA & NA & NA & NA & NA & 1 & 1 & 1 & 1 & 1 \\
\hline HOPE Score & $96 \%$ & $17 \%$ & $28 \%$ & $1 \%$ & $96 \%$ & NA & NA & NA & $13 \%$ & NA & $54 \%$ & $74 \%$ & $22 \%$ & $98 \%$ & $85 \%$ \\
\hline
\end{tabular}

acases not eligible for analysis of primary outcome because of missing data

b cases for which missing data for blood gas analysis of either central or peripheral potassium were replaced by central laboratory data

peripheral venous $(n=13$ patients), central venous and arterial ( $n=12$ patients), and peripheral venous and arterial potassium ( $\mathrm{n}=12$ patients).

When considering BGA analysis, on average, there was a trend for central venous potassium to be lower than peripheral potassium (median difference of 0.31 , IQR $-0.8-+0.75)$, but this difference was not statistically significant (Wilcoxon signed-rank test $p=0.6245$ ). On

Table 2 Summary of potassium values according to the sampling sites and analytical method used

\begin{tabular}{llll}
\hline & Median (IQR) & Mean \pm SD & Range \\
\hline Blood gas analyser & & & \\
Central venous $(n=12)$ & $4.36(3.09-7.57)$ & $5.66 \pm 3.76$ & $2.2-14.6$ \\
Femoral artery $(n=14)$ & $4.75(3.71-11.2)$ & $7.09 \pm 4.46$ & $2.5-15$ \\
Peripheral venous $(n=12)$ & $4.55(3.65-7.4)$ & $5.77 \pm 3.23$ & $2.6-13$ \\
Central laboratory & & & \\
Central venous $(n=11)$ & $3.8(3.1-6.4)$ & $4.95 \pm 2.84$ & $2.1-11.3$ \\
Femoral artery $(n=11)$ & $4.8(4.04-10.3)$ & $7.05 \pm 5.08$ & $3-19$ \\
Peripheral venous $(n=11)$ & $4.2(3.4-6.4)$ & $5.72 \pm 4.25$ & $2.3-17.2$ \\
\hline
\end{tabular}

average, the arterial potassium was higher than both the central and peripheral venous potassium (median difference of, respectively, $0.3 \mathrm{mmo} / \mathrm{L}$ (IQR $-0.05-+0.745$ ) and $0.445 \mathrm{mmol} / \mathrm{L}$ (IQR $-0.43-+1.425$ ), but these differences were not statistically significant $(P$ value for Wilcoxon signed-rank test of, respectively, 0.0914 and 0.1361). The Bland-Altman analysis of the difference between the 3 sampling sites is presented in Fig. 2. There was no agreement between potassium values according to the 3 different sampling sites using BGA.

When considering $\mathrm{CL}$ analysis, arterial potassium was significantly higher than central or peripheral venous potassium, as no significant difference was found between central and peripheral venous potassium (Additional file 1). When comparing the two analytic methods (BGA and CL), we found no significant difference regarding central venous, peripheral or arterial potassium values (Fig. 3).

\section{Discussion}

The average difference in potassium concentration between central and peripheral venous samples was lower than $1 \mathrm{mmol} / \mathrm{L}$ in our prospective study of hypothermic 

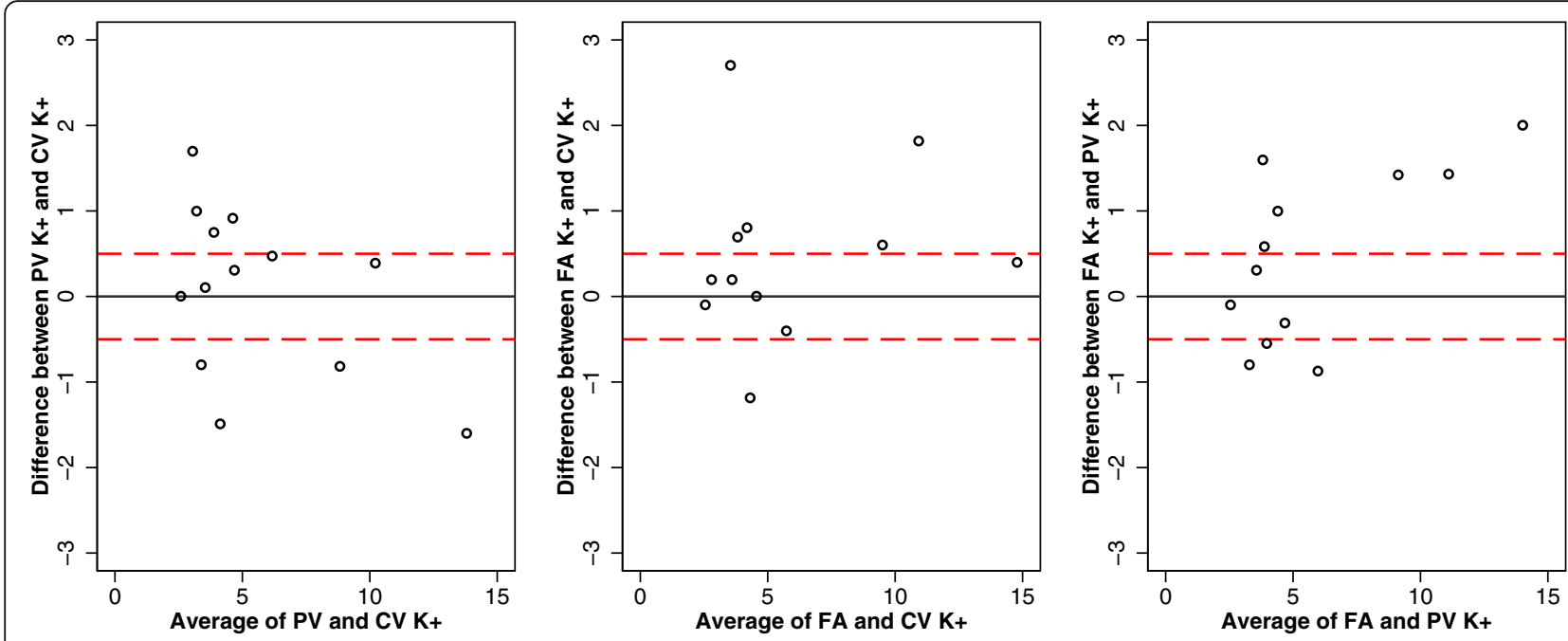

Fig. 2 Bland-Altman analysis of the difference in potassium between the three sampling sites when analysed by blood gas analyser. For each comparison, the mean value between the two sites is plotted against their difference. Red dash lines represent the $\pm 0.5 \mathrm{mmol} / \mathrm{L}$ upper and lower limits of standard criteria for acceptable performance for potassium. $C V=$ central vein; $F A=$ femoral artery; $K+=$ potassium; $P V=$ peripheral vein

CA patients. However, there was no agreement between potassium values according to the three different sites of sampling using BGA. Our study may have some important clinical implications.

\section{Clinical implications of the differences found in potassium concentration between sampling sites}

Potassium is one of the main triage tools, and the only biological marker used in clinical practice when deciding to rewarm a hypothermic CA patient [1, 8-10]. Hypothermia initially causes a decrease in the potassium level, due to an intracellular shift [23]. The presence of hyperkalaemia in deep hypothermia is a sign of irreversible cellular lysis and of a poor prognosis [5, 6, 23]. The highest potassium rate in a survivor of accidental hypothermia was $11.8 \mathrm{mmol} / \mathrm{L}$, in a child [24]. The highest recorded levels of potassium were $9 \mathrm{mmol} / \mathrm{L}$ [25] and $6.4 \mathrm{mmol} / \mathrm{L}$ in an adult who was successfully
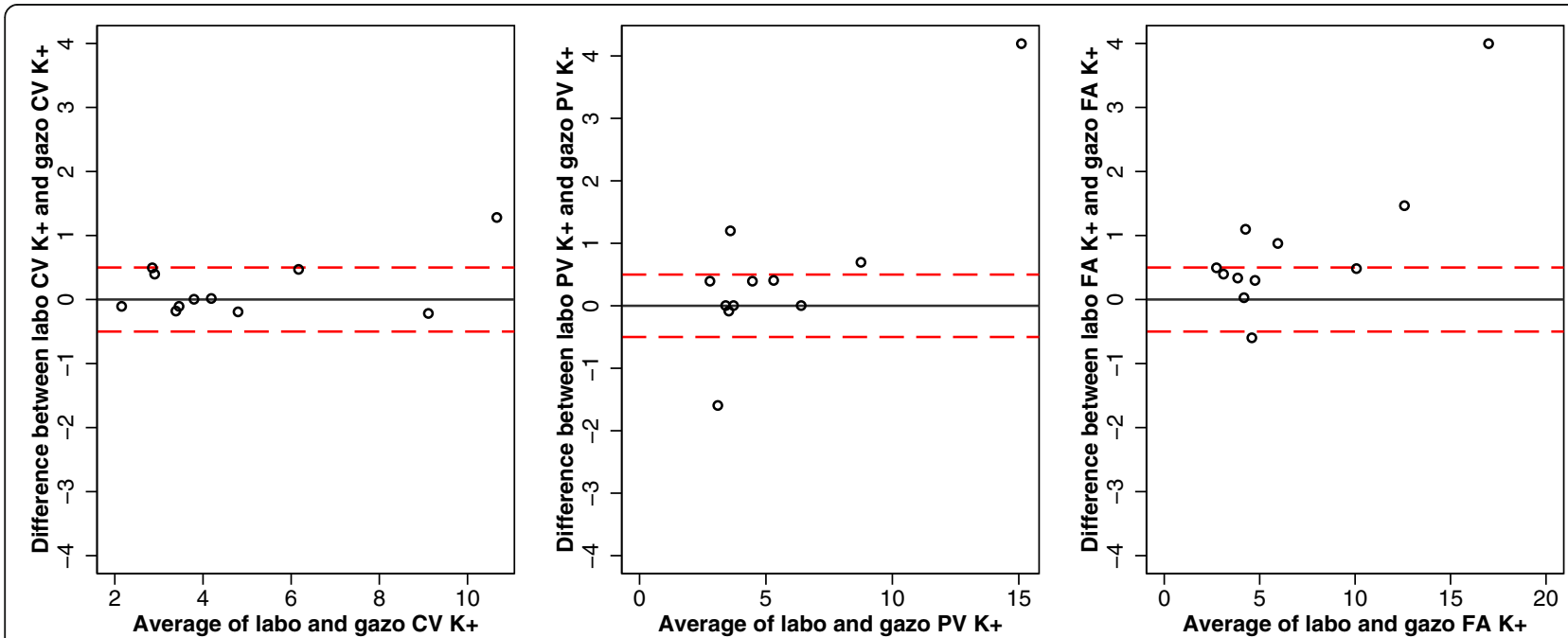

Fig. 3 Bland-Altman analysis of the difference in potassium between the two analytic methods for each of the three sampling sites. For each comparison the mean value of potassium for each of the two analytic methods (blood gas analyser or central labolatory) is plotted against their difference. Red dash lines represent the $\pm 0.5 \mathrm{mmol} / \mathrm{L}$ upper and lower limits of standard criteria for acceptable performance for potassium. The mean difference in potassium obtained from the central vein between the blood gas analyser and central labolatory was $0.81(p=0.0208)$. The mean difference in potassium obtained from the peripheral vein between the blood gas analyser and central labolatory was $0.51(p=0.1491)$. The mean difference in potassium obtained from the artery between the blood gas analyser and central labolatory was $0.17(p=0.5042)$. BGA = blood gas analyser; $\mathrm{CL}=$ central laboratory $(\mathrm{CL}) ; \mathrm{K}+=$ potassium 
resuscitated from hypothermic $\mathrm{CA}$ and an avalanche victim, respectively [26]. A potassium level $<12 \mathrm{mmol} / \mathrm{L}$ in a hypothermic CA patient usually indicates ECLS rewarming [1]. In contrast, with a potassium level $\geq 12$ $\mathrm{mmol} / \mathrm{L}$, cessation of reanimation efforts should be considered $[1,9,10]$. Lower potassium cut-offs have been proposed for avalanche victims, namely $8 \mathrm{mmol} / \mathrm{L}$ or, more recently, $7 \mathrm{mmol} / \mathrm{L}[1,8,10,27,28]$. According to our results, the observed differences in potassium analysed by BGA between the different sites of sampling would not have reclassified a single patient if the decisions to qualify a CA patient for ECLS rewarming were based on the potassium cut-offs of 7,8 or $12 \mathrm{mmol} / \mathrm{L}$. Only one patient would have been classified differently according to the sampling site when considering CL analysis. This patient had an arterial potassium of 13.3 $\mathrm{mmol} / \mathrm{L}$ and central venous potassium of $11.3 \mathrm{mmol} / \mathrm{L}$, which would have resulted in denying ECLS to this patient if a cut-off of $12 \mathrm{mmol} / \mathrm{L}$ arterial potassium had been applied.

The proposed standard criteria for acceptable performance for potassium is the target of $\pm 0.5 \mathrm{mmol} / \mathrm{L}[16$, 29]. A difference of $1 \mathrm{mmol} / \mathrm{L}$ may be clinically relevant and influence patient management options [15]. Such commonly accepted values may be revised to lower figures in the specific setting of hypothermic CA. In the latter situation, potassium has been used for decades in a dichotomous way to distinguish between ECLS indication (and potential for survival with good neurological outcome) and death. The maximal difference between, respectively, central venous and peripheral venous potassium measurements was $1.7 \mathrm{mmol} / \mathrm{L}$, which is far above this threshold. Moreover, our limits of agreement between central and peripheral venous potassium were 1.8 and $+2.0 \mathrm{mmol} / \mathrm{L}$, which is far broader than the standard criteria of $\pm 0.5 \mathrm{mmol} / \mathrm{L}$. The clinical consequence would be to underestimate the patient's potential for survival. Practically speaking, if using the actual dichotomous potassium triage, this would mean denying a patient with the potential to survive access to ECLS rewarming. This is especially important in the situation of hypothermic CA patients, for whom this would signify the death of the patient, as survivors following ECLS rewarming have much better neurological outcomes than survivors of normothermic CA [30]. Based on the important variations in the potassium level we found in this study within the same patient, we assume that the potassium level is not reliable as a single indicator for decision-making.

Life-or-death decisions based on a single parameter, much less a biological one, are rare in medicine, and our results underline the fragility and confirm the inadequacy of the "potassium-only" triage of hypothermic CA patients [31]. Our study results may therefore directly influence practice in several ways. First, if only one sampling site is used, then central venous sampling should be preferred. Also not statistically significant, the $-0.31 \mathrm{mmol} / \mathrm{L}$ difference in central venous potassium compared with peripheral potassium may represent a difference that is no longer considered acceptable [32], and that may be clinically significant in the very specific setting of hypothermic CA. Another reason to choose central venous potassium may be that, although peripheral sampling may avoid some complications linked to central blood sampling, such as iatrogenic trauma to the femoral vessels [33], it may be extremely technically challenging to obtain a peripheral sample, as shown by some of our study cases. Given the relative ease of obtaining femoral compared with peripheral venous blood sampling as well as the trend for central venous potassium to be lower than the peripheral one, we would propose to use central venous blood as the preferred site for a single potassium sampling. Another solution may be to perform multisite potassium sampling and decide using the lowest value of potassium. The important differences we found in both directions between sampling sites may support this latter proposal. Whatever potassium value is used, all has to be done to limit pseudohyperkalaemia, which would cause a falsely elevated potassium, possibly leading to inappropriate therapeutic decisions. Finally, the use of a multivariable dedicated tool like the HOPE score to guide decision-making should be promoted to increase the reliability of the decision to administer ECLS rewarming [4].

\section{Origin of the differences in potassium values between the different samplings}

The variations found in potassium concentration depending on the site of sampling may be explained by several reasons. First, differences may occur due to local factors [11-14]. This may arise in cases of hypothermic $\mathrm{CA}$, where phenomena like peripheral ischemia, crush syndrome due to immobilization, or circulation shifts may influence the local potassium concentration, notably between peripheral (accumulation) and central blood. Another reason may be pseudo-hyperkalaemia, which may also occur during or after blood collection, due to excessive tourniquet time or mechanical trauma during venepuncture or transport $[13,14,34]$. This may be the case especially in hypothermia, where the puncture or catheterization of vessels is often difficult, notably due to the difficulty in identifying a pulse in cardiac arrest patients [33] and where numerous attempts to puncture the vessels are common [33]. The use of ultrasound, which has been recommended to prevent this [33], or sampling through an in-place femoral catheter, was designed not only to ensure the correct sampling site but also to minimize the risk of haemolysis. In contrast, the 
fact that peripheral venous samples were not obtained in some cases because of technical difficulties may signify problems with these samples, which may have more elevated potassium through haemolysis, which has been shown to be especially prevalent in the emergency department [35].

\section{Clinical implications of the differences found in potassium concentration between analytical methods}

The type of analytical technique for potassium measurement (BGA or CL) is not specified in the recommendations. Some studies showed that potassium was lower if measured by BGA than if measured by $\mathrm{CL}[15,17,18]$. Like other authors, we were unable to find any significant difference in potassium measurement by BGA compared with CL in our study [36]. This point might, however, not be clinically very relevant in such emergency situations, where blood samples and BGA results are obtained in a few minutes, which is especially attractive or important in clinical scenarios where time is of the utmost importance [17, 18]. Although in hypothermia low flow duration is less important than in normothermic CA, short low flow is an independent factor for survival in hypothermic CA, and waiting for $\mathrm{CL}$ analysis is not even an option to consider [4]. Our results underline the reliability of BGA compared with laboratory analysis. As we found no significant difference between the two methods, BGA results can be considered valid for a value which should under no circumstances be subjected to variation.

\section{Limitations}

Our study suffers from several limitations. First, potassium measurement may be subject to important preanalytical bias [36]. Some of these biases - notably haemolysis of blood samples taken during CPR - may be especially important in the specific setting of hypothermic CA, where blood sampling is often difficult, notably due to the difficulty in identifying a pulse in these patients [33]. We did not plan to control - as suggested by some [36] - haemolysis in our study, notably because under real-life conditions this would not be feasible given the delay in obtaining results from the CL. However, we tried to minimize this bias regarding central sampling by the following methods that may be used in similar situations: sampling through an in-place catheter, or by vessel puncture under visual or ultrasonographic control, including by momentarily stopping reanimation. Second, we did not specify the drawing method for peripheral blood sampling. It has been showed that the risk of haemolysis is higher when the sample originates from an intravenous catheter compared with blood drawn by a straight needle [35]. However, direct puncture is often considered impractical in settings like the ED, where intravenous catheters are placed quasi-systematically and their use is recognized as virtually unavoidable [35, 37]. Furthermore, in our setting most patients arrive at the hospital with a peripheral catheter already placed by the emergency medical services (EMS).

\section{Conclusions}

In a cohort of consecutive hypothermic CA patients, we did not find an average difference in potassium concentration higher than $1 \mathrm{mmol} / \mathrm{L}$ between central and peripheral venous samples. However, we found important and clinically significant variability in potassium values between central venous, peripheral venous and arterial sampling sites. Our results suggest that the site of lowest potassium, and therefore the preferred site for a single potassium sampling is central venous blood. Analysis of serial samplings from different sites may be an alternative, if clinically feasible. Preanalytical considerations are important, to lower the risk of bias (falsely elevated potassium), which might signify, in the specific case of a hypothermic CA patient, the unjustified cessation of reanimation efforts. BGA is a fast and reliable tool that should be preferred to the CL in hypothermic CA. The use of multivariable prediction tools like the HOPE score may help mitigate the risks inherent in the limits of potassium measurement.

\section{Supplementary information}

Supplementary information accompanies this paper at https://doi.org/10. 1186/s13049-019-0694-3.

Additional file 1. Bland-Altman analysis of the difference in potassium between the three sampling sites when analysed by the central laboratory. For each comparison the mean value of potassium for each of the two sites is plotted against their difference. Red dash lines represent the $\pm 0.5 \mathrm{mmol} / \mathrm{L}$ upper and lower limits of standard criteria for acceptable performance for potassium. The mean difference was $0.26(p=0.153)$, when comparing central venous and peripheral potassium. The mean difference was 0.83 $(p=0.0143)$, when comparing central venous and arterial potassium. The mean difference was 0.68 ( $p=0.0511$ when comparing peripheral venous and arterial potassium. $\mathrm{BGA}=$ blood gas analyser; $\mathrm{CL}=$ central laboratory $(\mathrm{CL})$; $\mathrm{CV}=$ central vein; $\mathrm{FA}=$ femoral artery; $\mathrm{K}+=$ potassium; $\mathrm{PV}=$ peripheral vein.

\section{Abbreviations \\ BGA: Blood gas analysis; CA: Cardiac arrest; CL: Clinical laboratory analysis; CPC: Cerebral Performance Category; CPR: Cardiopulmonary resuscitation; ECLS: Extra-corporeal life support; EMS: Emergency medical services; IQR: Interquartile ranges; PEA: Pulseless electrical activity; ROSC: Return of a spontaneous circulation}

\section{Acknowledgements}

Pierre Audoin; Cyrielle Clape; Vincent Darioli; Marie-France Derkenne; Hélène Gerhardt-Donnet; Caroline Sanchez; Caroline Thyess; Frank Zeiter; Tobias

Zingg. The authors also acknowledge pre-hospital emergency teams, emergency physicians and anaesthesiologists for patient inclusion, ED nurses for peripheral samplings and anaesthesiologists for central ones.

\section{Authors' contributions}

$M P, M B, S B, B B$ and $P B$ conceived and designed the study. $M P, S B, B B$, and $\mathrm{PB}$ drafted the manuscript. MP, SB, BB, and PB conducted the data analysis. 
$M P, S B, B B$, and PB performed the statistical analysis. MB, GD, MK, MDR, PS, and TA critically revised the manuscript. All authors read and approved the final manuscript.

\section{Funding}

The study received financial support from Région Auvergne-Rhones-Alpes and from Siemens Company.

\section{Availability of data and materials}

The datasets generated and/or analysed during the current study are not publicly available but are available from the corresponding author on reasonable request.

\section{Ethics approval and consent to participate}

The study was approved by the institutional review board of the participating centres (Lausanne and Sion: CER-VD N² 201601760 and Grenoble: ID-RCB: 2016-A01762-49).

\section{Consent for publication}

Not applicable.

\section{Competing interests}

The authors declare that they have no competing interests.

\section{Author details}

'Emergency Department, Lausanne University Hospital, Lausanne, Switzerland. ${ }^{2}$ Department of Emergency Medicine, SAMU 38, University Hospital of Grenoble Alps, Grenoble, France. ${ }^{3}$ Department of Cardiac Surgery, Lausanne University Hospital, Lausanne, Switzerland. ${ }^{4}$ Emergency Department, Sion Hospital, Sion, Switzerland. ${ }^{5}$ Department of Anesthesiology, Lausanne University Hospital, Lausanne, Switzerland. ${ }^{6}$ Klinik für Anästhesiologie und Operative Intensivmedizin, University Hospital of Cologne, Köln, Germany. ${ }^{7}$ Department of anesthesiology and critical care, Grenoble Alps Trauma Center, University Hospital of Grenoble, Grenoble, France.

Received: 17 September 2019 Accepted: 3 December 2019

Published online: 16 December 2019

\section{References}

1. Brown DJ, Brugger H, Boyd J, Paal P. Accidental hypothermia. New England J Med. 2012:367:1930-8.

2. Debaty G, Moustapha I, Bouzat P, Maignan M, Blancher M, Rallo A, et al. Outcome after severe accidental hypothermia in the French Alps: a 10-year review. Resusc. 2015;93:118-23.

3. Walpoth BH, Walpoth-Aslan BN, Mattle HP, Radanov BP, Schroth G, Schaeffler $L$, et al. Outcome of survivors of accidental deep hypothermia and circulatory arrest treated with extracorporeal blood warming. New England J Med. 1997;337:1500-5.

4. Pasquier $M$, Hugli $O$, Paal $P$, Darocha $T$, Blancher $M$, Husby $P$, et al. Hypothermia outcome prediction after extracorporeal life support for hypothermic cardiac arrest patients: the HOPE score. Resusc. 2018;126: 58-64.

5. Schaller MD, Fischer AP, Perret $\mathrm{CH}$. Hyperkalemia. A prognostic factor during acute severe hypothermia. JAMA. 1990;264:1842-5.

6. Hauty MG, Esrig BC, Hill JG, Long WB. Prognostic factors in severe accidental hypothermia: experience from the Mt. Hood Tragedy J Trauma. 1987;27: 1107-12.

7. Boue Y, Payen JF, Brun J, Thomas S, Levrat A, Blancher $M$, et al. Survival after avalanche-induced cardiac arrest. Resusc. 2014;85:1192-6.

8. Truhlar A, Deakin CD, Soar J, Khalifa GE, Alfonzo A, Bierens JJ, et al. European resuscitation council guidelines for resuscitation 2015: section 4. Cardiac arrest in special circumstances. Resusc. 2015;95:148-201.

9. Zafren K, Giesbrecht GG, Danzl DF, Brugger H, Sagalyn EB, Walpoth B, et al. Wilderness medical society practice guidelines for the out-of-hospital evaluation and treatment of accidental hypothermia. Wilderness Environ Med. 2014;25:425-45.

10. Paal P, Gordon L, Strapazzon G, Brodmann Maeder M, Putzer G, Walpoth B, et al. Accidental hypothermia-an update : The content of this review is endorsed by the International Commission for Mountain Emergency Medicine (ICAR MEDCOM). Scand J Trauma Resusc Emerg Med. 2016;24:111.
11. Don BRSA, Cheitlin M, Christiansen M, Schambelan M. Pseudohyperkalemia caused by fist clenching during phlebotomy. New England J Med. 1990;322: 1290-2.

12. Whiffin $A N H$, Spangler JD, Dhir K, Zhang R, Ferguson JD. Bathroom entrapment leading to cardiac arrest from crush syndrome. Prehosp Emerg Care. 2019;23:90-3.

13. Meng QH, Wagar EA. Pseudohyperkalemia: a new twist on an old phenomenon. Crit Rev Clin Lab Sci. 2015;52:45-55.

14. McCaughey EJ, Vecellio E, Lake R, Li L, Burnett L, Chesher D, et al. Key factors influencing the incidence of hemolysis: a critical appraisal of current evidence. Crit Rev Clin Lab Sci. 2017;54:59-72.

15. Acikgoz SB, Genc AB, Sipahi S, Yildirim M, Cinemre B, Tamer A, et al. Agreement of serum potassium measured by blood gas and biochemistry analyzer in patients with moderate to severe hyperkalemia. Am J Emerg Med. 2016:34:794-7.

16. Prakash S, Bihari S, Lim ZY, Verghese S, Kulkarni H, Bersten AD. Concordance between point-of-care blood gas analysis and laboratory autoanalyzer in measurement of hemoglobin and electrolytes in critically ill patients. J Clin Lab Anal. 2018.

17. Gavala A, Myrianthefs P. Comparison of point-of-care versus central laboratory measurement of hematocrit, hemoglobin, and electrolyte concentrations. Heart Lung. 2017:46:246-50.

18. Altunok I, Aksel G, Eroglu SE. Correlation between sodium, potassium, hemoglobin, hematocrit, and glucose values as measured by a laboratory autoanalyzer and a blood gas analyzer. Am J Emerg Med. 2018.

19. Cummins RO, Chamberlain DA, Abramson NS, Allen M, Baskett PJ, Becker L, et al. Recommended guidelines for uniform reporting of data from out-ofhospital cardiac arrest: the Utstein style. A statement for health professionals from a task force of the American Heart Association, the European resuscitation council, the Heart and Stroke Foundation of Canada, and the Australian resuscitation council. Circ. 1991;84:960-75.

20. Safar P. Resuscitation after brain ischemia. In: GAaSP E, editor. Brain failure and resuscitation. New York: Churchill Livingstone; 1981. p. 155-84.

21. Ouweneel DM, Schotborgh JV, Limpens J, Sjauw KD, Engström AE, Lagrand WK, et al. Extracorporeal life support during cardiac arrest and cardiogenic shock: a systematic review and meta-analysis. Intensive Care Med. 2016:42: 1922-34.

22. Bland JM, Altman DG. Measuring agreement in method comparison studies. Stat Methods Med Res. 1999;8:135-60.

23. Buse $\mathrm{S}$, Blancher $\mathrm{M}$, Viglino $D$, Pasquier M, Maignan $M$, Bouzat $P$, et al. The impact of hypothermia on serum potassium concentration: a systematic review. Resusc. 2017;118:35-42.

24. Dobson JA, Burgess JJ. Resuscitation of severe hypothermia by extracorporeal rewarming in a child. J Trauma Acute Care Surg. 1996:40:483-5.

25. Pasquier M, Darocha T, Husby P. Survival of a cardiac arrested victim with hypothermia despite severely elevated serum potassium (9.0 mmol/L) Cryobiology. 2017;78:128-9.

26. Locher $\mathrm{T}$, Walpoth $\mathrm{BH}$. Differential diagnosis of circulatory failure in hypothermic avalanche victims: retrospective analysis of 32 avalanche accidents. Praxis (Bern 1994). 1996;85:1275-82

27. Brugger H, Durrer B, Elsensohn F, Paal P, Strapazzon G, Winterberger E, et al. Resuscitation of avalanche victims: evidence-based guidelines of the international commission for mountain emergency medicine (ICAR MEDCOM): intended for physicians and other advanced life support personnel. Resusc. 2013:84:539-46.

28. Brugger $H$, Bouzat $P$, Pasquier M, Mair $P$, Fieler J, Darocha T, et al. Cut-off values of serum potassium and core temperature at hospital admission for extracorporeal rewarming of avalanche victims in cardiac arrest: a retrospective multi-Centre study. Resusc. 2019;139:222-9.

29. Electronic Code of Federal Regilations (e-CFR). Title 42: Public Health. Regulations part 493 Laboratory Requirements, subpart I Proficiency testing programs by specialty and subspecialty, section 493.931 routine chemistry. Available at : https://www.law.cornell.edu/cfr/text/42/493.931

30. Pasquier M, Paal P, Blancher M, Darocha T. Higher survival chances of hypothermic vs. normothermic cardiac arrest patients with ECLS rewarming. Resusc. 2018

31. Gibbison B, Reeves BC. Forecasting HOPE: Risk prediction in rare events. Resusc. 2019:139:361-2

32. Fincher RK, Strong JS, Jackson JL. Accuracy of measurements of hemoglobin and potassium in blood samples from peripheral catheters. Am J Crit Care. 1998;7:439-43. 
33. Jarosz A, Kosinski S, Darocha T, Paal P, Gałązkowski R, Hymczak H, et al. Problems and pitfalls of qualification for extracorporeal rewarming in severe accidental hypothermia. J Cardiothorac Vasc Anesth. 2016;30:1693-7.

34. Vos MJ, Bouwhuis JW, Dikkeschei LD. A brother and sister with fluctuating potassium concentrations. Clin Chem. 2019;65:378-80.

35. Lippi G, Cervellin G, Mattiuzzi C. Critical review and meta-analysis of spurious hemolysis in blood samples collected from intravenous catheters. Biochemia Medica. 2013:193-200.

36. Monneret D. Potassium as a potential predictive biomarker of brain hypoxia in avalanche victims: preanalytical recommendations. Am J Emerg Med. 2016:34:1315-6.

37. Lippi G, Avanzini P, Cervellin G. Prevention of hemolysis in blood samples collected from intravenous catheters. Clin Biochem. 2013;46:561-4.

\section{Publisher's Note}

Springer Nature remains neutral with regard to jurisdictional claims in published maps and institutional affiliations.

Ready to submit your research? Choose BMC and benefit from:

- fast, convenient online submission

- thorough peer review by experienced researchers in your field

- rapid publication on acceptance

- support for research data, including large and complex data types

- gold Open Access which fosters wider collaboration and increased citations

- maximum visibility for your research: over $100 \mathrm{M}$ website views per year

At BMC, research is always in progress.

Learn more biomedcentral.com/submissions 